\title{
Proceeding
}

Supplementary Issue: Summer Conferences of Sports Science. Costa Blanca Sports Science Events, 20-21 September 2019. Alicante, Spain.

\section{Efficacy of 12 weeks of proprioceptive training in patients with multiple sclerosis}

\author{
PATRIZIA PROIA ${ }^{1}$, ALESSANDRA AMATO ${ }^{1}$, ROSALIA PULEO ${ }^{1}$, FRANCESCO ARNETTA ${ }^{1}$, FEDERICA \\ RIZZO'1, LICIA DI GRIGOLI'1, DANIELE ZANGLA', GIUSEPPE SCHIRÒ2², PAOLO RAGONESE², \\ GIUSEPPE MESSINA ${ }^{1}$ \\ ${ }^{1}$ Department of Psychological, Pedagogical and Educational Sciences, Sport and Exercise Sciences \\ Research Unit, University of Palermo, Italy \\ ${ }^{2}$ Department of Experimental Biomedicine and Clinical Neurosciences (BIONEC), University of Palermo, Italy
}

\begin{abstract}
This pilot study aims to investigate if specific training protocol can improve the quality of life in people with multiple sclerosis through the improvement of some impaired ability like the balance. We enrolled in our project 20 subjects (age: $34,88 \pm 4,45$; height: $168,25 \pm 8,66 \mathrm{~cm}$; weight: $72,31 \pm 17,28 \mathrm{~kg}$ ) but only 5 completed the study. A proprioceptive training was administered for 12 weeks, 2 times a week, an hour for each session. At the beginning (T0) and at the end of the study (T1), static and dynamic balance parameters were tested. Statistical analyzes were performed using IBM SPSS Statistics 22. Changes in balance and strength between T0, T1 were evaluated using $t$ Student test for paired data. Pearson linear correlation coefficient was used to investigate the correlations between all parameters analyzed. As regards static baropodometry, there was a statistic significant different between left forefoot

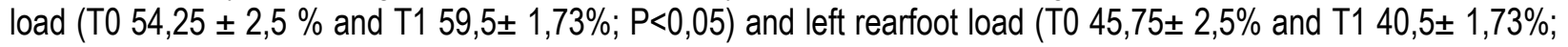
$\mathrm{P}<0,05)$. In dynamic baropodometry we gave more attention to three parameters: left length gait line (T0 176 $\pm 23,58$ and T1 215 $\pm 18,64(\mathrm{~mm}) ; P<0,05)$, right surface (T0 106,75 $\pm 14,97$ and $T 1149 \pm 11,58(\mathrm{~cm}) ; P<0,05)$ and right pressure point (T0 1050 \pm 130,90 and T1 537,25 $\pm 65,46$ ( $\mathrm{gr} / \mathrm{cm}) ; P<0,05)$. In conclusion, it is possible to hypothesize that the application of proprioceptive treatment in patients with multiple sclerosis can improve gait stability and therefore the walking. However, further studies, with a greater number of subjects, are necessary to confirm this trend. Keywords: Dynamic balance; Neurodegenerative disease; Baropodometry; Proprioceptive training.
\end{abstract}

\section{Cite this article as:}

Proia, P., Amato, A., Puleo, R., Arnetta, F., Rizzo, F., Di Grigoli, L., Zangla, D., Schirò, G., Ragonese, P., \& Messina, G. (2019). Efficacy of 12 weeks of proprioceptive training in patients with multiple sclerosis. Journal of Human Sport and Exercise, 14(5proc), S1986-S1992. doi:https://doi.org/10.14198/jhse.2019.14.Proc5.19

\footnotetext{
Corresponding author. Department of Psychological, Pedagogical and Educational Sciences, Sport and Exercise Sciences Research Unit, University of Palermo, Palermo-90128, Italy. https://orcid.org/0000-0002-0326-5560

E-mail: patrizia.proia@unipa.it

Supplementary Issue: Summer Conferences of Sports Science. Costa Blanca Sports Science Events, 20-21 September 2019. Alicante, Spain.

JOURNAL OF HUMAN SPORT \& EXERCISE ISSN 1988-5202

(c) Faculty of Education. University of Alicante

doi:10.14198/jhse.2019.14.Proc5.19
} 


\section{INTRODUCTION}

Multiple Sclerosis (MS) is a chronic inflammatory demyelinating disease causing injuries of the central nervous system (CNS), whose aetiology is still unknown although it has been ascertained its autoimmune nature (Bianconi et al., 2006). MS is characterized by many elements such as increased of lactate levels (Amorini, 2014), as well as in other pathologies like fibromyalgia (Proia, 2019), that could contribute in the alterations in gait and balance (Fritz et al., 2015). There are also some intriguing hypotheses that lactate may have a positive effect in many physiological as well pathological conditions, including brain aging and counteract neurodegenerative diseases (Proia et al., 2013). Physical activity can help MS patients manage symptoms, prevent some complications and also improve the quality of life which is considered a product resulting from physical, mental and social well-being (Giesser, 2015; Di Liegro et al, 2019). In this regard, numerous studies have shown that physical exercise, in MS patients not only induced neuroprotective effect, but also improved strength, mobility, static and dynamic balance. There are several different physical exercises that can induce a benefit in MS patients. For example, it has been shown as aerobic training protocol, consisting of 3 weekly sessions a cycloergometer, induced a 22\% improvement in $\mathrm{VO}_{2}$ max (Gallien et al., 2007). In another study it was shown as 8 weeks of aerobic dance, induced an improvement in the lipid profile, particularly on LDL cholesterol reduction and HDL cholesterol increase, in women with relapsingremitting multiple sclerosis (RRMS) (Monazamnezhad et al., 2015). Opposite to these founds, Heine et al. in 2017 highlighted, as 16 weeks of aerobic training, 3 sessions per week, performed on 89 patients with severe fatigue, did not lead to a clinically significant reduction of fatigue. As to concern the anaerobic training protocols it seems to be well tolerated by MS patients: in fact, many authors have found an improvement in muscle strength. In fact, a study that included a resistance training of 12 weeks, induced positive effects on strength, but also in fatigue's reduction (Dalgas et al., 2010). Taylor et al. highlighted in another study a significant increase in arm strength, leg strength and walking speed (2006). Regarding to strength training, the study by De Souza Teixeira et al. (2009) showed significant increases of the maximum voluntary contraction, maximum power and muscular endurance. As discussed above, the topic of our study was to investigate the effect of a proprioceptive training protocol (with aerobic/anaerobic exercises, flexibility and balance) on the quality of life of MS patients, reducing the symptoms of the disease and improving balance, posture and strength or rather physical and mental health.

\section{MATERIALS AND METHODS}

\section{Subjects}

At the Multiple Sclerosis Center of the Neurology "Paolo Giaccone" Hospital, 20 MS patients were recruited, with the following inclusion criteria (Table 1).

Table 1. Inclusion criteria.

- Age between 20 and 55;

- Absence of clinical relapses, in the 12 months preceding the study;

- Total score not less than 3.5 and not more than 5.5 in the EDSS;

-Absence of other concomitant diseases (tumours, epilepsy, diseases severe cardiovascular, osteoporosis, etc.);

- Informed consent by the patient;

- Presence of severe or moderate spasticity in at least one district upper limbs and a lower limb district. 
Among the 20 recruited patients only 5 completed; the reasons of the desertions were: personal reasons (2 subjects), relapsing of the disease (2 subjects), work commitments and unexpected diseases (11 subjects) (Table 2).

Table 2. Means \pm SEM of anthropometrics data.

\begin{tabular}{cccc}
\hline Patients number & Age & Height (cm) & Weight $\mathbf{( k g )}$ \\
\hline 5 & $34.88 \pm 4.45$ & $168.25 \pm 8.66$ & $72.31 \pm 17.28$ \\
\hline
\end{tabular}

\section{Dynamic and postural evaluations at $\mathrm{TO}$ and $\mathrm{T1}$}

At the beginning (T0) and at the end of the 12 weeks (T1) of the training protocol, the following assessments were made: stabilometry and baropodometry static and dynamic in order to verify the effect of the protocol on the balance and the posture. Specifically, a "Sensor Medica" platform was used. The evaluations were made in three ways: static with open and closed eyes and dynamic open eyes. According to international standards (AFP85), the feet were positioned at $30^{\circ}$ respect to static and parallel analysis for dynamics (Figure $1 \mathrm{~A})$. This method allows us a qualitatively and quantitatively postural oscillations analysis of the subjects placed in orthostatic in neutral posture and analyse the postural strategies used for maintenance balance (Figure 1 B). Instead, the baropodometric analysis was performed in 2 ways, static and dynamic:

- Static baropodometric analysis. It is possible to extract information on the pressure points on the ground of the foot during the standing position and also to measure the load, or the percentage of pressure between right and left foot, and the surface, or the surface occupied by the feet.

- Dynamic baropodometric analysis. Is the gait analysis during walking.

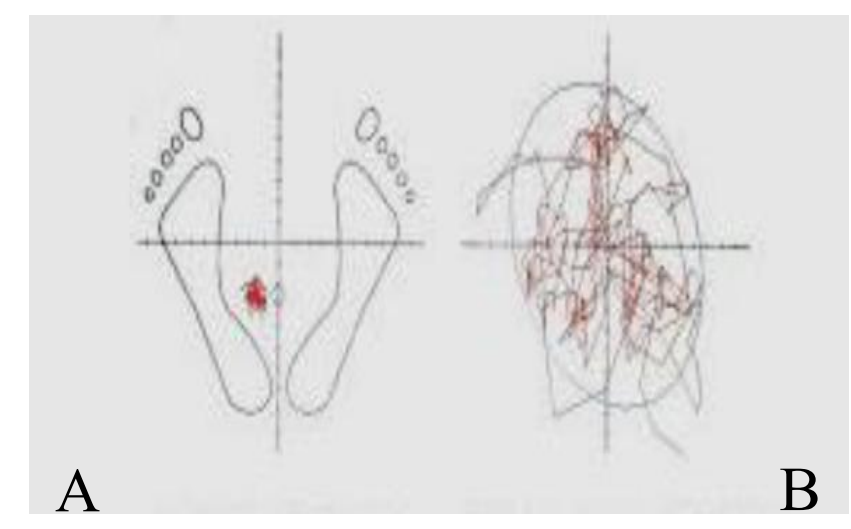

Figure 1. A, feet position; B, postural oscillation.

\section{Proprioceptive protocol}

A proprioceptive training was administered for 12 weeks, 2 times a week an hour for each session consisting of three different parts:

Warm up. Proprioceptive walk, with particular attention to the correct plantar support and swing of the arms, with oculo-motor reset exercises aimed at strengthening the proprioception in walking with closed eyes removing, for a few seconds, the visual influence in the regulation of balance. Furthermore, exercises were administered aimed at recover and/or enhance joint mobility.

Work out. Exercises performed with elastic bands, sitting, in feet or lying down and barefoot. For each exercise 3 series of 10 repetitions were indicated, with recovery of 60 seconds. 
Cool down. Stretching exercises and diaphragmatic and thoracic breathing.

\section{Statistical analysis}

Statistical analyses were performed using IBM SPSS Statistics 22. Changes in balance and strength between T0, T1 were evaluated using t Student test for paired data.

\section{RESULTS}

As regards static baropodometry, before to start the protocol, patients had: $54,25 \pm 2,5 \%$ of load on left forefoot and $45,75 \pm 2,5 \%$ of load on rearfoot. After training program, the load distribution was $59,5 \pm 1,73 \%$ for forefoot and 40,5 $\pm 1,73$ for rearfoot (Table 3). In dynamic baropodometry we gave more attention to three parameters: left length gait line (T0: $176 \pm 23,58$; and T1: $215 \pm 18,64 ;(\mathrm{mm}) ; \mathrm{P}<0,05)$, right surface (T0:

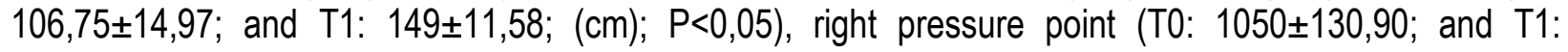
$537,25 \pm 65,46 ;(\mathrm{gr} / \mathrm{cm}) ; P<0,05)$ (Table 4). Regarding postural analysis, both with eyes open and closed, the results are summarized in the following Table 5 .

Table 3. Means \pm SEM of the static baropodometry analysis.

\begin{tabular}{lcc}
\hline \multicolumn{3}{c}{ Static baropodometry } \\
\hline T0 & Forefoot Load SX \% & RearFoot load SX \% \\
T1 & $54.25 \pm 2.5$ & $45.75 \pm 2.5$ \\
P value & $59.5 \pm 1.73$ & $40.5 \pm 1.73$ \\
\hline
\end{tabular}

Table 4. Means \pm SEM of the dynamic baropodometry analysis.

\begin{tabular}{|c|c|c|c|c|c|c|c|}
\hline \multicolumn{8}{|c|}{ Dynamic baropodometry } \\
\hline & \multirow[b]{2}{*}{$\begin{array}{l}\text { Left Length } \\
\text { Gait Line } \\
(\mathrm{mm})\end{array}$} & \multirow[b]{2}{*}{$\begin{array}{l}\text { Right Surface } \\
(\mathrm{cm})\end{array}$} & \multirow[b]{2}{*}{$\begin{array}{l}\text { Right Average } \\
\text { pressure point } \\
\text { (gr/cm) }\end{array}$} & \multicolumn{4}{|c|}{ Load distribution } \\
\hline & & & & $\begin{array}{l}\text { Left forefoot } \\
(\%)\end{array}$ & $\begin{array}{l}\text { Left rear } \\
\text { foot }(\%)\end{array}$ & $\begin{array}{l}\text { Right } \\
\text { forefoot } \\
(\%)\end{array}$ & $\begin{array}{l}\text { Right rear } \\
\text { foot }(\%)\end{array}$ \\
\hline TO & $176 \pm 23.58$ & $106.75 \pm 14.97$ & $1050 \pm 130.90$ & $72.25 \pm 11.79$ & $62 \pm 7.53$ & $\begin{array}{l}27.75 \pm \\
11.79\end{array}$ & $38 \pm 7.52$ \\
\hline $\mathrm{T} 1$ & $215 \pm 18.64$ & $149 \pm 11.58$ & $537.25 \pm 65.46$ & $62 \pm 4.55$ & $66.75 \pm 4.27$ & $38 \pm 4.55$ & $33.25 \pm 4.27$ \\
\hline \multirow{2}{*}{$\begin{array}{l}P \\
\text { value }\end{array}$} & $\mathrm{t}: 0.01^{*}$ & $\mathrm{t}: 0.03^{*}$ & $\mathrm{t}: 0.01^{*}$ & $\mathrm{t}: 0.08$ & $\mathrm{t}: 0.41$ & $\mathrm{t}: 0.26$ & $\mathrm{t}: 0.41$ \\
\hline & $P<0.05$ & $P<0.05$ & $P<0.05$ & $P>0.05$ & $P>0.05$ & $P>0.05$ & $P>0.05$ \\
\hline
\end{tabular}

Table 5. Means \pm SEM of postural analysis.

\begin{tabular}{llllllll}
\hline \multicolumn{3}{c}{ Open eyes } & \multicolumn{5}{l}{ Closed eyes } \\
\hline & $\begin{array}{l}\text { Ellipse surface } \\
(\mathrm{cm})\end{array}$ & $\begin{array}{l}\text { Length of clew } \\
(\mathrm{mm})\end{array}$ & $\begin{array}{l}\text { Walk } \\
\text { velocity } \\
(\mathrm{mm} / \mathrm{s})\end{array}$ & $\begin{array}{l}\text { Ellipse surface } \\
(\mathrm{cm})\end{array}$ & $\begin{array}{l}\text { Length of clew } \\
(\mathrm{mm})\end{array}$ & $\begin{array}{l}\text { Walk velocity } \\
(\mathrm{mm} / \mathrm{s})\end{array}$ \\
\hline $\mathrm{T0}$ & $392.3 \pm 202.80$ & $632.56 \pm 59.23$ & $12.98 \pm 1.31$ & $2859.47 \pm 2817.73$ & $1427.24 \pm 723.62$ & $28.29 \pm 14.35$ \\
\hline T1 & $399.04 \pm 374.53$ & $671.55 \pm 160.43$ & $13.42 \pm 3.16$ & $812.29 \pm 235.30$ & $1006.44 \pm 364.23$ & $19.72 \pm 7.03$ \\
\hline $\begin{array}{l}P \\
\text { value }\end{array}$ & $\mathrm{t}: 0.98 \mathrm{P}>0.05$ & $\mathrm{t}: 0.7 \mathrm{P}>0.05$ & $\mathrm{t}: 0.83 \mathrm{P}>0.05$ & $\mathrm{t}: 0.29 \mathrm{P}>0.05$ & $\mathrm{t}: 0.5 \mathrm{P}>0.05$ & $\mathrm{t}: 0.48 \mathrm{P}>0.05$ \\
\hline
\end{tabular}

\footnotetext{
${ }^{*}$ Significant differences at the 0.05 level.
} 


\section{DISCUSSION}

Multiple sclerosis is a neurodegenerative disease that can affect several districts such as brain, spinal cord, optic nerves; it is characterized by different symptoms that compromise the quality of life of the subject as walking disorder. Recently Fritz et al. pointed out as analysis of walking could describe the level of the disease emphasizing the relationship between gait alteration and pathology (2017). Our study aims were to perform a qualitative, as well as a quantitative, evaluations in MS patients of the effects of a proprioceptive training protocol on walking. However, the difference before and after treatment on right gait length was not statistically significant, but the trend was positive (T0 $164 \pm 36.17$ and T1 $185.75 \pm 35.73$ (mm); P> 0,05); by this way the symmetry is maintained between left and right gait length but in a wider and therefore more stable gait length.

As concern the value's average of pressure point on the right side, it was significantly decreased after the proprioceptive training period ( $P=0,01$ ) (Table 4). Meyring et al. (1997) shows the influence of the spasticity on the plantar pressure that results greater compare with the patients without spasticity, attributing this phenomenon to the sensory deficits and considering it a protective mechanism. Consequently, the effectiveness of our protocol, even applied for a short time, decreased plantar pressure during stride: this can play a role to help to limit this common spasticity-associated problem that affects walking ability and improve quality of life (Chang et al., 2002a; 2002b). This statistically significant effect was found only for the right foot. However, average pressure point on the left confirms the downward trend in pressure (T0 915,25 $\pm 187,03$ and T1 456,5 $\pm 232,16$ (gr/cm); $P>0,05)$. Hessert et al., 2005 has shown how the plantar pressure distribution in the MS patients were useful for monitoring the progression of the disease (Hessert et al., 2005) and it could also be caused by the hypertonic plantar flexor muscles that contribute to an altered distribution of weight (Molteni et al., 2002). Moreover, Hilal Keklicek et al., in 2018 showed that subjects with MS also have an abnormal load distribution during walking, in particular they have an exaggerated pressure in the forefoot, compared to healthy subjects. Our data shows a trend in decrease of the dynamic baropodometry, the distribution of pressure in the foot during the walk after treatment, the load in the forefoot and a trend in increase in the back particularly in the left foot (forefoot T0 $72,25 \pm 11,79 \%$ and $T 162 \pm 4,55 \%$; $P>0,05$ ). So, this seems to be another very positive outcome to improve the walk of people with multiple sclerosis and make them independent.

\section{CONCLUSIONS}

In conclusions our results show that proprioceptive treatment could be effective to improve the quality of life in patients with multiple sclerosis especially in walking stability, one of the impaired skills in this pathology. However, further studies, with a greater number of subjects and a longer treatment time, are necessary to confirm this trend.

\section{REFERENCES}

Amorini, A.M., Nociti, V., Petzold, A., Gasperini, C., Quartuccio, E., Lazzarino, G., Di Pietro, V., Belli, A., Signoretti, S., Vagnozzi, R., Tavazzi, B. (2014). Serum lactate as a novel potential biomarker in multiple sclerosis. Biochim Biophys Acta; 1842:1137-1143. https://doi.org/10.1016/j.bbadis.2014.04.005

Bianconi, G., Poggioli, E., Merelli, E., Razzaboni, E., Comelli, D. (2006). Aspetti psicologici della sclerosi multipla,.G Ital Med Lav Erg. 28:1, Suppl Psicologia 1, 22-28. https://doi.org/10.1007/978-88-470$\underline{2724-4 \_16}$ 
Chang, C.H., Albarracin, J.P., Lipton, G.E., Miller, F., (2002). Long-term follow- up of surgery for equinovarus foot deformity in children with cerebral palsy. J. Pediatr. Orthop. 22, 792-799. https://doi.org/10.1097/01241398-200211000-00020

Chang, C.H., Miller, F., Schuyler, J., (2002). Dynamic pedobarograph in evaluation of varus and valgus foot deformities. J. Pediatr. Orthop. 22, 813-818. https://doi.org/10.1097/01241398-200211000$\underline{00023}$

Dalgas, U., Stenager, E., Jakobsen. J., Petersen, T., Hansen, H.J., Knudsen, C., Overgaard, K., Ingemann-Hansen, T. (2010). Fatigue, mood and quality of life improve in MS patients after progressive resistance training. Mult Scler;; 16:480-490. https://doi.org/10.1177/1352458509360040

De Souza, T., Costilla, S., Ayán, C., García-López, D., Gonzá lez-Gallego, J., de Paz, A.J. (2009) Effects of Resistance Training in Multiple Sclerosis. Int J Sports Med; 30: 245 - 250. https://doi.org/10.1055/s-0028-1105944

Di Liegro, C.M., Schiera, G., Proia, P., Di Liegro, I. (2019).Physical Activity and Brain Health.Genes (Basel). 10(9). pii: E720. https://doi.org/10.3390/genes10090720

Fritz, N.E., Keller, J., Calabresi, P.A., Zackowski, K.M. (2017). Quantitative measures of walking and strength provide insight into brain corticospinal tract pathology in multiple sclerosis. MSNeurolmage: Clinical 14 490-498. https://doi.org/10.1016/j.nicl.2017.02.006

Fritz, N.E., Newsome, S.D., Eloyan, A., Marasigan, R.E., Calabresi, P.A., Zackowski, K.M. (2015). Longitudinal relationships among posturography and gait measures in multiple sclerosis. Neurology;84:2048-2056. https://doi.org/10.1212/wnl.0000000000001580

Gallien, P., Nicolas, B., Robineau, S., Pétrilli, S., Houedakor, J., Durufle, A. (2007).Physical training and multiple sclerosis. Ann Readapt Med Phys. Jul;50(6):373-6, 369-72. https://doi.org/10.1016/..annrmp.2007.04.004

Giesser. (2015). Exercise in the management of persons with multiple sclerosis Ther. Adv in Neurol Disord. 8(3): 123-130. https://doi.org/10.1177/1756285615576663

Heine, M., Verschuren, O., Hoogervorst, E.L., van Munster, E., Hacking, H.G., Visser-Meily, A., Kwakkel, G. (2017). Does aerobic training alleviate fatigue and improve societal participation in patients with multiple sclerosis? A randomized controlled trial; Mult scler. ott; 23 (11): 1517-1526. https://doi.org/10.1177/1352458517696596

Hessert, M.J., Vyas, M., Leach, J., Hu, K., Lipsitz, L.A., Novak, V., (2005). Foot pressure distribution during walking in young and old adults. BMC Geriatr. 5 (1), 8. https://doi.org/10.1186/1471-2318-5$\underline{8}$

Keklicek, H., Cetin, B., Salci, Y. , Balkan, A.F., Altinkaynak, U., Armutlu, K.(2018) Investigating the dynamic plantar pressure distribution and loading pattern in subjects with multiple sclerosis. Mult Scler Relat Disord. Feb;20:186-191. https://doi.org/10.1016/j.msard.2018.01.023

Meyring, S., Diehl, R.R., Milani, T.L., Hennig, E.M., Berlit, P., (1997). Dynamic plantar pressure distribution measurements in hemiparetic patients. Clin. Biomech. 12 (1), 60-65. https://doi.org/10.1016/s0268-0033(96)00050-2

Molteni, F., Bertoni, M., Caimmi, M., (2002). Equinovarus foot in upper motor neuron syndrome. In: Esquenazi, A. (Ed.), Gait Analysis. Hanley \& belfus, Philadelphia, pp. 263-286.

Monazamnezhad, A., Habibi. A., shakeriyan, S., Majdinasab, N., Ghalvand, A. (2015). The Effects of Aerobic Exercise on Lipid Profile and Body Composition in Women With Multiple Sclerosis. https://doi.org/10.5812/ijcdc.26619

Proia, P., Amato, A., Contrò, V., Monaco, A.L., Brusa, J., Brighina, F., Messina, G. (2019). Relevance of lactate level detection in migrane and fibromyalgia. Eur J Transl Myol. ;29(2):8202. https://doi.org/10.4081/ejtm.2019.8202 
Proia, P., Di Liegro, C.M., Schiera, G., Fricano, A., Di Liegro, I. (2016). Lactate as a Metabolite and a Regulator in the Central Nervous System. Int $J$ Mol Sci;17:1450. https://doi.org/10.3390/ijms17091450

Taylor, N.F., Dodd, K.J., Prasad, D., Denisenko, S. (2006). Progressive resistance exercise for people with multiple sclerosis. Disabil Rehabil; 28: 1119-26. https://doi.org/10.1080/09638280500531834 